\title{
Transmitted drug resistance mutations and subtype diversity amongst HIV-1 sero- positive voluntary blood donors in Accra, Ghana
}

Billal Musah Obeng ${ }^{1,2^{*}}$, Evelyn Yayra Bonney ${ }^{1}$, Lucy Asamoah-Akuoko ${ }^{3}$, Nicholas Israel Nii-Trebi ${ }^{4}$, Gifty Mawuli ${ }^{1}$, Christopher Zaab-Yen Abana ${ }^{1}$ and Kwamena William Coleman Sagoe ${ }^{2^{*}}$

\begin{abstract}
Background: Detection of HIV-1 transmitted drug resistance (TDR) and subtype diversity (SD) are public health strategies to assess current HIV-1 regimen and ensure effective therapeutic outcomes of antiretroviral therapy (ART) among HIV-1 patients. Globally, limited data exist on TDR and SD among blood donors. In this study, drug resistance mutations (DRMs) and SD amongst HIV-1 sero-positive blood donors in Accra, Ghana were characterized.

Methods: Purposive sampling method was used to collect 81 HIV sero-positive blood samples from the Southern Area Blood Center and confirmed by INNO-LIA as HIV-1 and/or HIV-2. Viral RNA was only extracted from plasma samples confirmed as HIV-1 positive. Complementary DNA (CDNA) was synthesized using the RNA as a template and subsequently amplified by nested PCR with specific primers. The expected products were verified, purified and sequenced. Neighbour-joining tree with the Kimura's 2-parameter distances was generated with the RT sequences using Molecular Evolutionary Genetic Analysis version 6.0 (MEGA 6.0).

Results: Out of the 81 plasma samples, 60 (74\%) were confirmed as HIV-1 sero-positive by INNO-LIA HIVI/II Score kit with no HIV-2 and dual HIV-1/2 infections. The remaining samples, 21 (26\%) were confirmed as HIV sero-negative. Of the 60 confirmed positive samples, (32) 53\% and (28) 47\% were successfully amplified in the RT and PR genes respectively. Nucleotide sequencing of amplified samples revealed the presence of major drug resistance mutations in two (2) samples; E138A in one sample and another with K65R. HIV-1 Subtypes including subtypes A, B, CRF02_AG and CRFO9_cpx were found.

(Continued on next page)
\end{abstract}

\footnotetext{
* Correspondence: vifredobeng@gmail.com; kwcsagoe@chs.edu.gh

'Department of Virology, Noguchi Memorial Institute for Medical Research (NMIMR), University of Ghana, Accra, Ghana

2Department of Medical Microbiology, School of Medicine and Dentistry, University of Ghana, Accra, Ghana

Full list of author information is available at the end of the article
}

(c) The Author(s). 2020 Open Access This article is licensed under a Creative Commons Attribution 4.0 International License, which permits use, sharing, adaptation, distribution and reproduction in any medium or format, as long as you give appropriate credit to the original author(s) and the source, provide a link to the Creative Commons licence, and indicate if changes were made. The images or other third party material in this article are included in the article's Creative Commons licence, unless indicated otherwise in a credit line to the material. If material is not included in the article's Creative Commons licence and your intended use is not permitted by statutory regulation or exceeds the permitted use, you will need to obtain permission directly from the copyright holder. To view a copy of this licence, visit http://creativecommons.org/licenses/by/4.0/ The Creative Commons Public Domain Dedication waiver (http://creativecommons.org/publicdomain/zero/1.0/) applies to the data made available in this article, unless otherwise stated in a credit line to the data. 


\begin{abstract}
(Continued from previous page)
Conclusion: This study found major drug resistance mutations, E138A and K65R in the RT gene that confer high level resistance to most NNRTIs and NRTI respectively. CRF02_AG was most predominant, the recorded percentage of subtype $B$ and the evolutionary relationship inferred by phylogenetic analysis may suggest possible subtype importation. However, a more prospective and detailed analysis is needed to establish this phenomenon. The data obtained would inform the selection of drugs for ART initiation to maximize therapeutic options in drug-naive HIV1 patients in Ghana.
\end{abstract}

Keywords: HIV-1, Subtype diversity, Transmitted drug resistance, Blood donors

\section{Background}

The HIV global burden is estimated at 36.9 million infected persons with approximately 25 million living in Sub-Saharan Africa [1]. HIV-1 infection was first detected in Ghana in 1986 and has since been responsible for numerous deaths of both children and adults [2]. Currently, the prevalence of HIV-1 in Ghana is estimated to be $1.7 \%$ in 2017 [3].

A major therapeutic intervention to the HIV pandemic has been the introduction and access to antiretroviral therapy (ART) [4]. This has reduced HIV-related morbidity and mortality rates and increased life expectancy of infected individuals [5]. However, therapeutic success of these ARTs is reduced as a result of emergence of HIV-1 DRMs, viral SD and spontaneously generated polymorphisms due to immune pressure in patients receiving ARTs [6]. The absence of genotypic drug resistance monitoring may lead to patients harboring viruses with DRM which could be transmitted to new hosts, a phenomenon described as transmitted drug resistance (TDR) [7].

TDR is an important public health concern due to increased risk of virologic failure when ART is initiated [8]. Systematic studies have suggested higher rates of TDR (11-23\%) in Europe, America, and Australia, as compared to countries where scale-up of ART is ongoing [9-11]. In these studies, the prevalence of TDR in nucleoside reverse transcriptase inhibitors (NRTI), nonnucleotide reverse transcriptase inhibitors (NNRTI) and protease inhibitors (P1), were $7.4,3.4$ and $3 \%$ respectively.

Comprehensive care for people living with HIV/AIDS (PLHIV) in Ghana started in 2003 with first-line drugs including azidothymidine (AZT), stavudine (d4T), lamivudine (3TC), nevirapine (NVP) and efavirenz (EFV). Over the past decade, these drugs have expanded to include emtricitabine (FTC), tenofovir (TDF), and abacavir $(A B C)$. Since its inception, ART has been scaled up to about 40\% of HIV patients [3]. Limited data has shown that DRM and TDR in naïve PLHIV in Ghana are low [12-15]. A threshold survey among pregnant women in the administrative region where ART was first introduced in Ghana observed a TDR rate of $<5 \%$ [14].
Voluntary blood donors (VBD) provide a population base which is young and are more likely to have been recently exposed to HIV [16]. In order to understand the transmission dynamics among newly exposed people living with HIV (PLHIV), TDR in a cross-section of VBD needs to be assessed.

\section{Materials and methods \\ Study design and setting}

A cross-sectional study using purposive sampling method was conducted at the Southern Area Blood Center (SABC), Ghana from August 2016 to February 2017. The center is a satellite facility of the National Blood Service, Ghana (NBS). It is mandated to collect, screen, and distribute safe blood to various hospitals and clinics in the southern part of Ghana. The NBS recruits VBD using a questionnaire to first assess their behavioral risk factors and health status to ascertain their suitability to donate blood. Upon successful recruitment and blood donation, the blood is screened for HBsAg, HCV antibodies, HIV and antibodies for Treponema pallidum as procedures for safe blood. The test algorithm for HIV-1 at the blood bank is by the detection of p24 antigen using the HIV $(\mathrm{Ag} / \mathrm{Ab}) 4^{\text {thGen }}$ (Fortress Diagnostics Limited, Antrim, U.K). Currently, a more sensitive test tool such as the PCR and/or INNO-LIA is not employed.

\section{Ethics statement}

Ethical approval was obtained from the Ethics and Protocol Review Committee of the College of Health Sciences, University of Ghana. Approval to select HIV positive samples was also obtained from the NBS.

\section{Study participants}

A total of eighty-one (81) voluntarily donated blood samples that were rejected as been HIV sero-positive using the HIV $(\mathrm{Ag} / \mathrm{Ab}) 4^{\text {thGen }}$ (Fortress Diagnostics Limited, Antrim, U.K) were used. A data extraction sheet was used in obtaining information on age and gender from the donors' records upon approval from the SABC. Study numbers were assigned to anonymize the blood samples. 


\section{Sample collection and confirmation}

Plasma was obtained from the SABC and were transported in cold boxes with ice packs to the Virology Department of NMIMR and stored at $-30^{\circ} \mathrm{C}$ until further processing. A confirmatory test (INNO-LIA ${ }^{\mathrm{Tm}}$ HIV-I/II score, Fujirebio, Gent, Belgium) was done on all plasma samples following manufacturer's protocol.

\section{RNA extraction and complementary DNA (cDNA) synthesis}

Viral RNA was extracted using the QIAamp ${ }^{\circ}$ viral RNA mini kit (QIAGEN, Hilden, Germany) following manufacturer's protocol. A two-step reverse transcription method was used to generate complementary DNA (cDNA) of HIV-1 from extracted RNA using Transcriptor High Fidelity cDNA synthesis kit (Roche Diagnostics, Mannheim, Germany). An initial reaction mix of $2.0 \mu \mathrm{l}$ random hexamer primer, $2.4 \mu \mathrm{l}$ nuclease-free water and $7.0 \mu \mathrm{l}$ of extracted RNA were incubated at $65^{\circ} \mathrm{C}$ for 10 min and immediately placed on ice. A second reaction mix made up of $4.0 \mu \mathrm{l}$ of $5 \mathrm{X}$ High fidelity reverse transcriptase (5X HFRT) buffer, $0.5 \mu$ l protector RNAase inhibitor, $2.0 \mu \mathrm{l}$ deoxynucleotide triphosphates (dNTPs), $1.0 \mu \mathrm{l}$ dithiothreitol (DTT) and $1.1 \mu \mathrm{l}$ transcriptor HFRT enzyme was prepared. An aliquot of $8.6 \mu$ l of the second mix was added to the first reaction, thoroughly mixed and incubated at $45^{\circ} \mathrm{C}$ for $30 \mathrm{~min}$ followed by $85^{\circ} \mathrm{C}$ for $5 \mathrm{~min}$.

\section{Polymerase Chain reaction (PCR) amplification}

Nested PCR was done to separately amplify the protease (PR) and reverse transcriptase (RT) genes from the cDNA synthesized using the Expand High Fidelity ${ }^{\text {plus }}$ PCR kit (Roche Diagnostics, Mannheim, Germany) with specific primers and cycling conditions previously published [17]. In the first round, $5.0 \mu \mathrm{l}$ of $5 \times$ buffer with $\mathrm{MgCl}_{2}, 0.5 \mu \mathrm{l}$ of dNTPs, $1.0 \mu \mathrm{l}$ each of forward and reverse primers, $0.25 \mu \mathrm{l}$ of expand high fidelity polymerase and $12.25 \mu \mathrm{l}$ of nuclease free water were added to $5.0 \mu \mathrm{l}$ of cDNA. In the second round of the PCR, $5.0 \mu \mathrm{l}$ of $5 \mathrm{X}$ buffer with $\mathrm{MgCl}_{2}, 0.5 \mu \mathrm{l}$ dNTPs, $0.5 \mu \mathrm{l}$ of each of forward and reverse primers, $0.25 \mu \mathrm{l}$ expand high fidelity polymerase and $15.25 \mu \mathrm{l}$ nuclease-free water were added to $3.0 \mu \mathrm{l}$ of round 1 product. A fragment of 463 base pairs (bp) and $887 \mathrm{bp}$ for the PR and RT genes respectively, were generated and confirmed by agarose gel electrophoresis.

\section{Purification of PCR amplicons and cycle sequencing}

Purification of nested PCR products was done using QIAquick PCR purification kit (QIAGEN, Hilden, Germany) following manufacturer's protocol. Purified amplicons were eluted in $50 \mu \mathrm{l}$ of elution buffer for cycle sequencing. The BigDye Terminator v3.1 Cycle
Sequencing kit (Applied Biosystems, MA, U.S.A) was used to separately sequence the PR and RT genes of HIV-1 using primers and cycling conditions previously published [18]. A total reaction volume of $10 \mu \mathrm{l}$ comprising of $2 \mu \mathrm{l}$ each of a primer, BigDye terminator, BigDye terminator buffer, nuclease free water and purified PCR product was used. Sequenced products were purified using the Agencourt $^{\circledR}$ CleanSEQ ${ }^{\circledR}$ Dye-Terminator Removal system (Agencourt Bioscience Corporation, U.S.A) following manufacturer's protocol. The purified product was loaded onto the ABI 3130xl genetic analyzer (Applied Biosystems, MA, U.S.A) to generate sequence data for HIV-1 DRM and HIV subtype analyses.

\section{Sequence and phylogenetic analysis}

Nucleotide sequences for each sample were assembled to form a contig using SeqManPro 13 (DNASTAR Incorporation, U.S.A). Consensus sequence obtained was aligned with an HIV reference sequence (B-HXB2-PRT_ 2253-3700) in BioEdit (http://www.mbio.ncsu.edu/Bioedit/bioedit.html). Sequences were submitted to the Stanford University HIV Drug Resistance Database (https:// hivdb.stanford.edu/hivdb/by-sequences/) to assign subtypes detect HIV drug resistance mutations and. The subtypes were confirmed with the Los Alamos National Laboratory HIV Database (http://www.hiv.lanl.gov). Neighbor-joining tree with the Kimura's 2-parameter distances was generated with the RT sequences using Molecular Evolutionary Genetic Analysis version 6.0 (MEGA 6).

\section{Data analysis}

Statistical analysis was done using SPSS version 23 (Armonk, USA) to describe patients' demographics using frequencies and percentages.

\section{Results}

A total of eighty-one (81) HIV-1 sero-positive blood samples were selected from the blood bank for this study. The HIV status, age and gender characteristics of participants is summarized in Table 1. Majority (40\%) were between the ages of 26 to 35 years with 46 to 55 year group being the least recorded (10\%). Majority (74\%) were males whilst $14 \%$ were females. Age and Gender information for $10(12 \%)$ of the study samples were not available in the SABC donor records. Sixty (74\%) of the samples were confirmed as HIV-1 positive, Twenty-one samples (26\%) were found to be negative for HIV-1, HIV-2 or dual HIV-1/2 infection.

Of the 60 samples confirmed reactive for HIV-1, 28 (47\%) and 32 (53\%) were successfully amplified for the PR and RT genes respectively. Of these, 12/28 (43\%) and 20/32 (63\%) were successfully sequenced for the PR and 
Table 1 Demographic characteristics and HIV status of study samples

\begin{tabular}{ll}
\hline Variable & Frequency (\%) \\
\hline Age & \\
$\leq 25$ & $19(23)$ \\
$26-35$ & $32(40)$ \\
$36-45$ & $12(15)$ \\
$46-55$ & $8(10)$ \\
N/A & $10(12)$ \\
Gender & \\
Male & $60(74)$ \\
Female & $11(14)$ \\
N/A & $10(12)$ \\
HIV Status & \\
HIV-1 & $60(74)$ \\
HIV-2 & $0(0)$ \\
HIV-1/2 & $0(0)$ \\
HIV Negative & $21(26)$ \\
Total & $81(100)$ \\
\hline
\end{tabular}

Table 1 indicates the HIV status, age and gender characteristics of participants. Majority (40\%) were between the ages of 26 to 35 years with 46 to 55 -year group being the least recorded (10\%). Majority (74\%) were males whilst $14 \%$ were females. Demographics for $10(12 \%)$ of the study samples were not available. Sixty (74\%) of the samples were confirmed as HIV-1 positive, Twenty-one samples (26\%) were found to be negative for HIV-1, HIV-2 or dual HIV-1/2 infection

Key: N/A Not Available, HIV Human Immunodeficiency Virus

RT genes respectively. Eight samples had sequences for both the PR and RT genes. One (1) sample had minor DRM in the PR gene whilst 1 minor and 2 major DRMs were found in the RT gene of three (3) samples as shown in Table 2.

Out of the 12 PR sequences, 1 (8\%) was subtype A, 2 (17\%) were subtype B and 9 (75\%) were CRF02_AG. Of the 20 RT sequences, 2 (10\%) were subtype A, 8 (40\%) were subtype B, 9 (45\%) were CRF02_AG and 1 (5\%) was CRF09_cpx as indicated in Fig. 1.

Table 2 Drug resistance mutations in samples successfully amplified and sequenced

\begin{tabular}{llll}
\hline Gene & Samples Amplified & Samples Sequenced & Samples with DRMs \\
\hline PR & 28 & 12 & 1 PI \\
RT & 32 & 20 & 2 NRTIs \\
& & & 1 NNRTIs
\end{tabular}

Table 2shows the number of samples successfully amplified and sequenced in the PR and RT genes of HIV-1. Twenty-eight (50\%) and $32(53 \%)$ were successfully amplified for the PR and RT genes respectively. Of these, 12/28 $(43 \%)$ and $20 / 32(63 \%)$ were successfully sequenced for the PR and RT genes respectively. One (1) sample had minor DRM in the PR gene whilst 1 minor and 2 major DRMs were found in the RT gene of three (3) samples Key: PR Protease, RT Reverse Transcriptase, PI Protease Inhibitor, NRT/s Nucleoside Reverse Transcriptase Inhibitors, NNRTIs Non-nucleoside Reverse Transcriptase Inhibitors
No major PR-related DRM was observed in the samples whilst major RT-related DRMs in two (2) samples were found; E138A in one sample and another with K65R. Drug resistance implications of the mutations found are shown in Table 3.

Phylogenetic analysis using the Neighbour-joining tree with the Kimura's 2-parameter distances was generated with the RT sequences using Molecular Evolutionary Genetic Analysis tool version 6.0 (MEGA6). Study samples were labelled with coloured squares (red, green, blue and black squares indicating different subtypes) and reference sequences labelled with accession numbers as shown in Fig. 2.

\section{Discussion}

This study examined occurrence of drug-resistance mutations in apparently healthy blood donors who tested positive for HIV-1.The proportion of males to females in this study does not concord with HIV-1 trends. The same could be said for the distribution of HIV infection across the age groups. Although, the number of females infected with HIV nationwide is more than males [2], voluntary blood donors are usually males. Females are usually disqualified due to relatively lower hemoglobin $\mathrm{Hb})$ levels. This is partly because of monthly blood loss during menstruation and the toll of pregnancy. Moreover, it is physically active men usually between the ages of 25-50 years who volunteer to donate blood. Thus, these reasons could have accounted for the pattern seen in this study.

The predominance of CRF02_AG and absence of HIV2 and dual HIV-1/2 infections agrees with studies reporting HIV-1 infection as the predominant HIV type in Ghana and CRF02_AG as the main subtype [19, 20]. The twenty (21) samples that were later confirmed to be HIV negative indicate the need for diagnostic methods with higher sensitivity at blood banks to minimize the probability of transfusing infected blood [10].

HIV-1 TDR occurs when recently infected individuals who are not exposed to antiretroviral drugs harbor drug resistant viruses. In this study, HIV-1 TDR is defined as the presence of at least one major HIV-1 DRM in a study participant. Two (2) major DRMs were found in two (2) samples sequenced in the RT gene (E138A and $\mathrm{K} 65 \mathrm{R})$ and none in the PR gene. Other mutations were also found, which do not confer drug resistance by themselves but only when they occur in combination with other mutations. The accessory and minor mutations found were F77L and L10F in RT gene and PR gene respectively.

The E138A mutation is a polymorphic mutation that occurs in an appreciable number of drug-naïve patients such as the population studied and confers resistance to etravirine (ETR) and rilpivirine (RPV), which are NNRT 
$\square$ A $\square$ CRF02_AG $\square$ CRF09_cpx

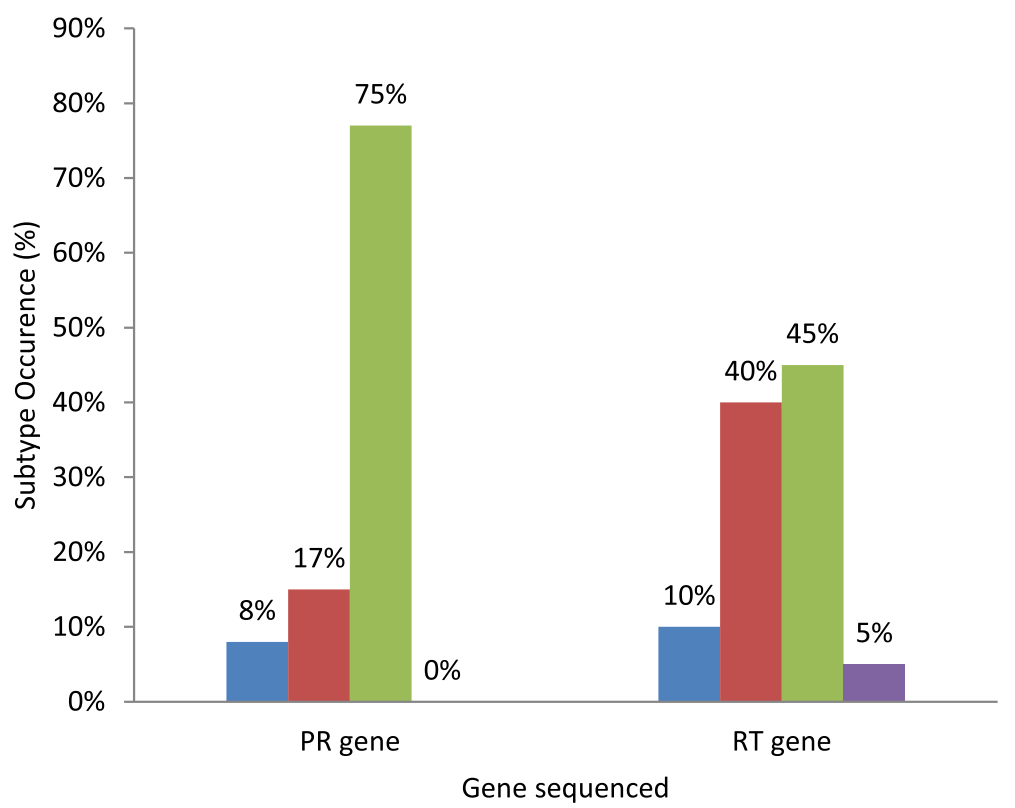

Fig. 1 Percentage occurrence of HIV-1 subtypes in sequenced PR and RT genes. Figure 1 shows HIV-1 Subtype patterns in the PR and RT genes. PR and RT sequences were submitted online to the Stanford University HIV Drug Resistance Database (HIVdb). One (8\%) was subtype A, 2 (17\%) were subtype B and 9 (75\%) were CRF02_AG. Of the 20 RT sequences, 2 (10\%) were subtype A, 8 (40\%) were subtype B, 9 (45\%) were CRF02_AG and 1 (5\%) was CRF09_cpx. Key: PR Protease, RT Reverse Transcriptase, CRF Circulating Recombinant Form

Is $[21,22]$. In a similar study, E138A was found in ARTnaïve pregnant women attending antenatal care in a teaching hospital in Accra, Ghana [23]. This mutation, has been shown to reduce susceptibility to ETR and RPV by 2 -folds. The K65R mutation is found to reduce viral susceptibility to most NRTIs by approximately 2fold and rather increase susceptibility to AZT and hence reduced viral replication with zidovudine-containing therapy [24].

Table 3 Drug resistance mutations (DRMs) found and implications on available drug regimen

\begin{tabular}{lllll}
\hline Study & Subtype & \multicolumn{2}{l}{ DRM } & ARV \\
\cline { 3 - 4 } & & PR & RT & \\
\hline 1 & CRF02_AG & - & F77L & ABC, AZT, D4T, DDI, TDF, 3TC, FTC \\
2 & CRF02_AG & L10F & - & FPV/r, IDV/r, NFV, LPV/r, \\
3 & CRF02_AG & - & E138A & ETR, RPV \\
4 & B & & K65R & ABC, AZT, D4T, DDI, TDF \\
\hline
\end{tabular}

Table 3 Indicates the PR and RT related DRMs found and their drug resistance implications on available antiretroviral drug regimen. No major PR-related DRM was observed in the samples whilst major RT-related DRMs in two (2) samples were found; E138A in one sample and another with K65R $N B:[A$ Alanine, $D$ Aspartate, $E$ Glutamate, $F$ Phenylalanine, $L$ Leucine, $V$ Valine, $K$ Lysine, $R$ Arginine, FPV/r Ritonavir-boosted fosamprenavir, IDV/r Ritonavirboosted indinavir, NFV Nelfinavir, $L P V / r$ Ritonavir-boosted lopinavir, $A B C$ Abacavir, AZT Zidovudine, D4T Stavudine, DDI Didanosine, TDF Tenofovir, 3TC Lamivudine, FTC Emtricitabine, ETR Etravirine, RPV Rilpivirine, NVP Nevirapine, EFV Efavirenz]

Key: CRF Circulating recombinant form
The findings of this study are consistent with other studies previously conducted among drug naïve infected individuals, in which PI-associated DRM were rarely found $[23,25]$. Generally, low level DRMs against PIs in the Ghanaian population could be attributed to the high genetic barrier of protease inhibitors and that the virus would have to mutate several times to develop resistance to such drugs. Additionally, sparing use of protease inhibitors reserved for use mostly in second-line regimen while majority of those on treatment are on reverse transcriptase inhibitors may have accounted for this phenomenon.

Viral sequence subtyping showed CRF02_AG as most predominant subtype in the study population. Other subtypes found were B, A and CRF09_cpx. This result is similar to some studies conducted in West Africa [26, 27] and in Ghana [19, 25]. The predominance of CRF02_AG has been associated with high viral infectivity and productivity, possible replicative fitness and high viral loads which favour viral transmission $[19,20]$. Subtype B was the next predominant subtype and was relatively frequent compared to previous studies in Ghana [25]. Subtype B is most predominant in the Americas $[28,29]$ and Western Europe [30, 31].

The occurrence of HIV-1 subtypes in different geographical areas has been linked to socio-epidemiologic factors such as mobility and migration [32, 33]. These factors, however, cannot be confirmed for this 


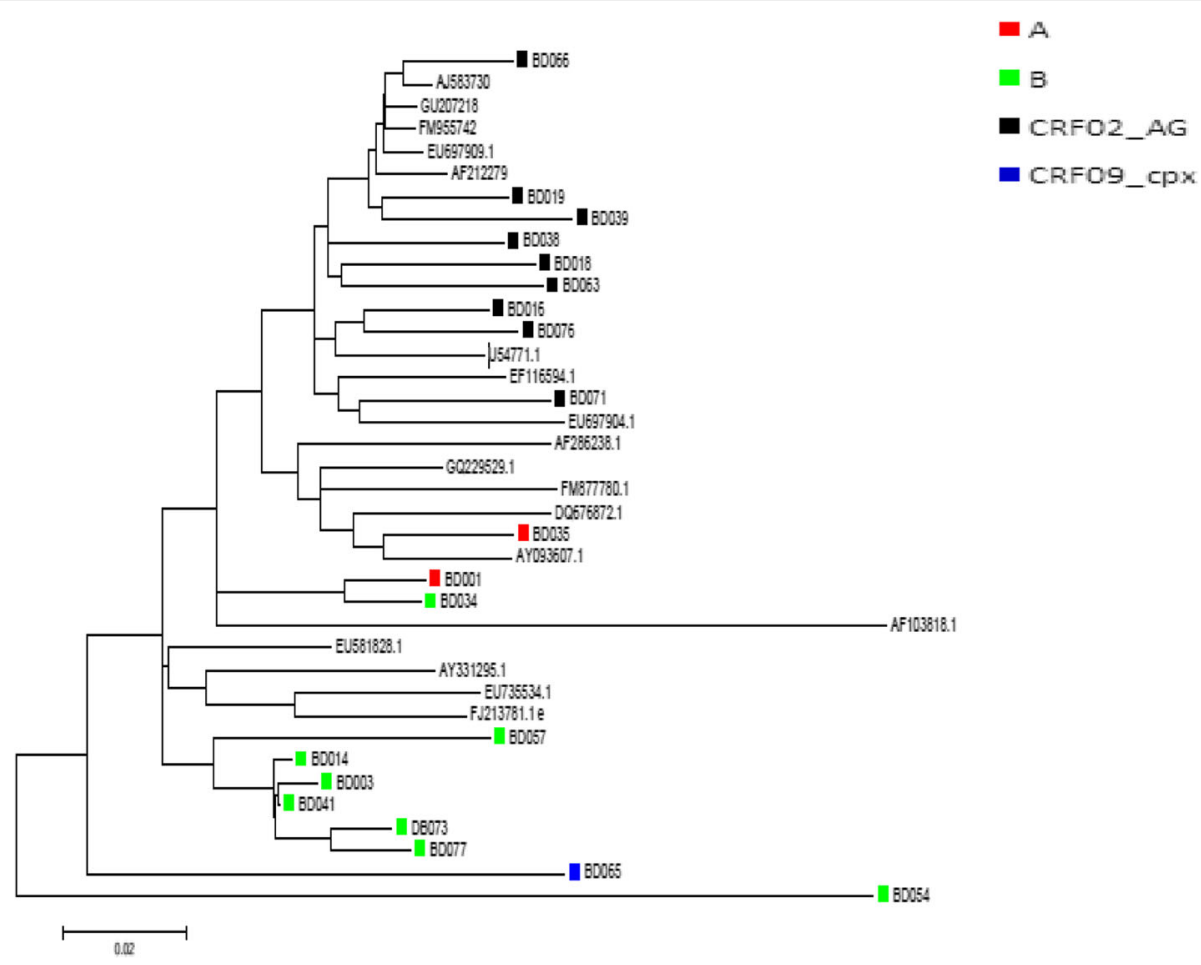

Fig. 2 Phylogenetic analysis of RT sequences of HIV-1 in the study. Figure 2 shows the phylogenetic analysis of RT sequences using Neighborjoining tree with the Kimura's 2-parameter distances generated with Molecular Evolutionary Genetic Analysis tool version 6.0 (MEGA6). Study samples were labelled with coloured squares (red, green, blue and black squares indicating different subtypes) and references labelled with accession numbers. Study sequences clustered around reference sequences from Nigeria, Cameroon, Kingdom of Saudi Arabia, Democratic Republic of Congo, United States of America, Peru, Uruguay and Britain. Key: CRF Circulating Recombinant Form

population due to lack of data on residence and citizenship of the participants studied. However, phylogenetic analysis revealed evolutionary relationship of studied sequences with reference sequences from Nigeria, Cameroon, Kingdom of Saudi Arabia, Democratic Republic of Congo, United States of America, Peru, Uruguay and Britain.

The study observed low amplification rate of samples. This could be due to low viral loads in some samples. However, it is not entirely the reason for low amplification rate as samples with low viral loads were successfully amplified whilst others with higher loads were not amplified. Previous research shows that samples from patients with persistently low viral load could be genotyped by a nested PCR method $[18,24]$.

The inability to obtain peripheral blood mononuclear cells (PBMC) to amplify alongside the plasma could also account for a lower amplification rate. Amplification success with proviral DNA from PBMC was found to be relatively higher than viral RNA from plasma $[22,26]$. Genotyping from plasma RNA and proviral DNA concurrently could have increased amplification success since some plasma samples may be amplified and not their PBMC samples and vice versa.
Despite these limitations, the study obtained data that is important for HIV management in Ghana.

\section{Conclusions}

This study found major drug resistance mutations, E138A and K65R that respectively confer high level resistance to NNRTIs and NRTIs. Although, CRF02_AG was most predominant, the recorded percentage of subtype $\mathrm{B}$ and the evolutionary relationship inferred by phylogenetic analysis may suggest possible subtype importation. A more prospective and detailed analysis is needed to establish this phenomenon. The data obtained is useful for the selection of drugs for ART initiation to maximize therapeutic outcomes in drug-naïve HIV-1 patients in Ghana. Continuous surveillance for drug resistance mutations and subtype diversity in population groups is therefore imperative for effective ART outcomes.

\section{Abbreviations}

ul: Microlitre; 3TC: Lamivudine; ABC: Abacavir; ABI: Applied Biosystems Inc; ART: Antiretroviral Therapy; ARV: Antiretroviral; ATV: Atazanavir;

AZT: Zidovudine; bp: Base pair; CDNA: Complementary DNA; CRF: Circulating Recombinant Form; D4T: Stavudine; DDI: Didanosine; DNA: Deoxyribonucleic Acid; DRM: Drug Resistance Mutation; DRV: Darunavir; ETR: Etravirine;

FI: Fusion Inhibitors; FPV: Fosamprenavir; FTC: Emtricitabine; HBsAG: Hepatitis B Surface Antigen; HBV: Hepatitis B Virus; HCV: Hepatitis C Virus; HIV- 
1: Human Immunodeficiency Virus type 1; HIVdb: HIV Database; HIVDR: HIV Drug Resistance; IDV: Indinavir; II: Integrase Inhibitors; KBTH: Korle-Bu Teaching Hospital; LPV: Lopinavir; NBS: National Blood Service; NFV: Nelfinavir; NNRTI: Non-nucleoside Reverse Transcriptase Inhibitors; NRTI: Nucleoside Reverse Transcriptase Inhibitors; NVP: Nevirapine; PCR: Polymerase Chain Reaction; PI: Protease Inhibitors; PR: Protease; RNA: Ribonucleic Acid; RPV: Rilpivirine; RT: Reverse Transcriptase; SABC: Southern Area Blood Centre; SD: Subtype Diversity; TDF: Tenofovir; THFRT: Transcriptor High Fidelity Reverse Transcriptase; TDR: Transmitted Drug Resistance; UNAIDS: Joint United Nations Programme on HIV/AIDS; WHO: World Health Organization

\section{Acknowledgements}

We thank the National Blood Service, Ghana for the samples used in this study. Technical support by the HIV genotyping team of Noguchi Memorial Institute for medical research is acknowledged.

\section{Sequence data}

The HIV-1 RT and PR sequences have been deposited at GenBank under accession numbers MN402725-MN402756.

\section{Data sharing statement}

The data sets are available with the corresponding author on request.

\section{Authors' contributions}

Conceived and designed the experiments: BMO, EYB, NIN-T, KWCS, LA-K; enrolled patients: BMO, LA-K, GM; performed the experiment: BMO, data management, analysis and interpretation: BMO, EYB, LA-K, GM; prepared the manuscript: BMO, EYB, NIN-T, KWCS; Read and approve the manuscript: BMO, EYB, NIN-T, KWCS, LA-K.

\section{Funding}

This research was supported by the Noguchi Memorial Institute for Medical Research Postdoctoral Training Fellowship Program, Bill and Melinda Gates Foundation.

\section{Availability of data and materials}

The data sets used and analysed during this study are available with the corresponding author on request.

\section{Ethics approval and consent to participate}

The protocol was approved by the Ethics and Protocol Review Committee of the College of Health Sciences, University of Ghana (CHS-Et/M.1 - P 3.2/ 2016-2017). Approval to select HIV positive samples was also obtained from the NBS (NBSGRD/160929/01).

\section{Consent for publication}

The NBS has given the consent to publish the results without personal identification.

\section{Competing interests}

No competing interest exist.

\begin{abstract}
Author details
'Department of Virology, Noguchi Memorial Institute for Medical Research (NMIMR), University of Ghana, Accra, Ghana. ${ }^{2}$ Department of Medical Microbiology, School of Medicine and Dentistry, University of Ghana, Accra, Ghana. ${ }^{3}$ Department of Research, National Blood Service, Accra, Ghana. ${ }^{4}$ Department of Medical Laboratory Sciences, School of Biomedical and Allied Health Sciences, University of Ghana, Accra, Ghana.
\end{abstract}

Received: 14 April 2020 Accepted: 15 July 2020

Published online: 24 July 2020

\section{References}

1. WHO. World AIDS Day Global Report. (2017). http://www.who.int. Accessed 13 Dec 2017.

2. NACP. HIV/AIDS in Ghana: Background, Projections, Impacts, Interventions and Policy. 3rd ed; 2000. http://www.policyproject.com/pubs/ countryreports/gha_aim3rded.pdf. Accessed 13 Dec 2017.
3. UNAIDS. Country factsheets, Ghana, 2017. (2018). https://www.unaids.org/ en/regionscountries/countries/ghana. Accessed 17 Dec 2018.

4. Kiptoo M, Brooks J, Lihana RW, Sandstrom P, Ng'ang'a Z, Kinyua J, et al. HIV1 drug resistance-associated mutations among HIV-1 infected drug-naïve antenatal clinic attendees in rural Kenya. BMC Infect Dis. 2013;13:517.

5. Palella FJ, Delaney KM, Moorman AC, Loveless MO, Fuhrer J, Satten GA, et al. Declining morbidity and mortality among patients with human immunodeficiency virus infection: HIV outpatient study investigators. N Engl Med. 1998;338:853-60

6. Richman DD, Morton SC, Wrin T, Hellmann N, Berry S, Shapiro M, et al. The prevalence of antiretroviraldrug resistance in the United States. AIDS. 2004; 18:1393-401.

7. Hamers RL. Transmitted HIV-1 drug resistance in Africa. Lusaka: 8th INTEREST workshop; 2014

8. Wittkop L, Gunthard HF, De Wolf F, Dunn D, Cozzi-Lepri A, De Luca A, et al. Effect of transmitted drug resistance on virological and immunological response to initial combination antiretroviral therapy for HIV (EuroCoordCHAIN joint project): a European multicohort study. Lancet Infect Dis. 2011; 11(5):363-71.

9. UNAIDSNHO. Report on the global epidemic. 2009. Available at www.unaids. org/en/HIV_data/2009GlobalReport/default.asp. Accessed 13 Feb 2016.

10. Weinstock HS, Zaidi I, Heneine W, Bennett D, Garcia-Lerma JG, Douglas JM, et al. The epidemiology of antiretroviral drug resistance among drug-naive HIV-1-infected persons in 10 US cities. J Infect Dis. 2004;189:2174-80.

11. Wensing AM, Van de Vijver DA, Angarano G, Asjö B, Balotta C, Boeri E, et al. Prevalence of drug-resistant HIV-1 variants in untreated individuals in Europe: implications for clinical management, SPREAD Programme. J Infect Dis. 2005;192:958-66.

12. Sagoe KWC, Dwidar M, Lartey M, Boamah I, Agyei AA, et al. Variability of the human immunodeficiency virus type 1 polymerase gene from treatment naive patients in Accra, Ghana. J Clin Virol. 2007:40:163-7.

13. Brandful JAM, Candotti D, Allain J-P. Genotypic diversity and mutation profile of HIV-1 strains in antiretroviral treatment (ART) -Naïve Ghanaian patients and implications for antiretroviral treatment (ART). J AIDS HIV Res. 2012;4(7):187-97.

14. Bonney EY, Ntim NAA, Addo-Yobo F, Bondzie P, Aryee KE, Barnor JS, et al. Low level of transmitted HIV drug resistance at two HIV care Centres in Ghana: a threshold survey. Ghana Med J. 2013;47(2):82-6.

15. Nii-Trebi NI, Ibe S, Barnor JS, Ishikawa K, Brandful JAM, Ofori SB, et al. HIV-1 drug-resistance surveillance among treatment-experienced and treatmentNalve patients after the implementation of antiretroviral therapy in Ghana. PLoS One. 2013:8:1-8.

16. UNAIDS. 'Update: Active involvement of young people is key to ending the AIDS epidemic by 2030'. 2015. https://www.avert.org/professionals/hivsocial-issues/key-affected-populations/young-people\#footnote1_qzpzzqd. Accessed 21 Mar 2017

17. Villahermosa ML, Thomson M, Vázquez de Parga E, Cuevas MT, Contreras G, Pérez-Alvarez $L$, et al. Improved conditions for extraction and amplificationof human immunodeficiency virus type 1RNA from plasma samples with low viral load. J Hum Virol. 2000;3(1):27-34.

18. Fujisaki S, Fujisaki S, Ibe $\mathrm{S}$, Asagi T, Itoh T, Yoshida $\mathrm{S}$, et al. Performance and quality assurance of genotypic drug-resistant testing for human immunodeficiency virus type 1 in Japan. Jpn J Infect Dis. 2007:60:113-7.

19. Nii-Trebi NI, Barnor JS, Obeng BM, Ampofo WK. Epidemiologic dominance of HIV-1 subtype CRF02 AG in Ghana: preliminary virological evidence of increasing association with new infections. Int J Virol Stud Res. 2016;4:22-8.

20. Fischetti L, Opare-Sem O, Candotti D, Lee H, Allain J-P. Higher viral load may explain the dominance of CRF02_AG in the molecular epidemiology of HIV in Ghana. AIDS. 2004;18:1208-10.

21. Haddad M, Napolitano LA, Paquet AC, Evans MD, Petropoulos CJ, Whitcomb $J$, et al. Impact of HIV-1 reverse transcriptase E138 mutations on rilpivirine drug susceptibility. Antivir Ther. 2011;16:A18.

22. Tambuyzer L, Nijs S, Daems B, Picchi G, Vingerhoets J. Effect of mutations at position E138 in HIV-1 reverse transcriptase on phenotypic susceptibility and virologic response to etravirine. J Acquir Immune Defic Syndr. 2011;58: $18-22$.

23. Martin-Odoom A, Adiku T, Delgado E, Lartey M, Ampofo WK. Occurrence of transmitted HIV-1 drug resistance among drug-naïve pregnant women in selected HIV care centers in Ghana. Ghana Med J. 2017;51:20-3.

24. Stephan C, Dauer B, Bickel M, Haberl A, Locher L, Muller A. Intensification of a failing regimen with zidovudine may cause sustained virologic 
suppression in the presence of re-sensitizing mutations including K65R. J Infect. 2010;61:346-50.

25. Booth CL, Geretti AM. Prevalence and determinants of transmitted antiretroviral drug resistance in HIV-1 infection. J Antimicrob Chemother. 2007:59:1047-56.

26. Mamadou S, Montavon C, Ben A, Dijibo A, Rabiou S, M'Boup S, et al. Predominance of CRF02-AG and CRF06-cpx in Niger, West Africa. AIDS Res Hum Retrovirus. 2002;18:723-6.

27. Njai HF, Gali Y, Vanham G. The predominance of human immunodeficiency virus type 1 (HIV-1) circulating recombinant form 02 (CRF02_AG) in west Central Africa may be related to its replicative fitness. Retrovirol. 2006;3:40.

28. Louwagie J, Delwart EL, Mullins JI, McCutchan FE, Eddy G, Burke DS. Genetic analysis of HIV-1 isolates from Brazil reveals the presence of two distinct genotypes. AIDS Res Hum Retrovirus. 1994;10:561-7.

29. Louwagie J, Janssens W, Mascola J, Heyndrickx L, Hegerich P, McCutchan FE, et al. Genetic diversity of the envelope glycoprotein from human immunodeficiency virus type 1 isolates of african origin. J Virol. 1995;69:26371.

30. Deroo S, Robert I, Fontaine E, Lambert C, Plesseria JM, Arendt V, et al. HIV-1 subtypes in Luxembourg, 1983-2000. AIDS. 2002;16:2461-7.

31. Tatt ID, Barlow KL, Clewley JP, Gill ON, Parry JV. Surveillance of HIV-1 subtypes among heterosexuals in England and Wales, 1997-2000. J Acquir Immune Defic Syndr. 2004;36:1096-9.

32. Tebit DM, Arts EJ. Tracking a century of global expansion and evolution of HIV to drive understanding and to combat disease. Lancet Infect Dis. 2011; 11:45-56.

33. Hemelaar J. The origin and diversity of the HIV-1 pandemic. Trends Mol Med. 2012;18:182-92.

\section{Publisher's Note}

Springer Nature remains neutral with regard to jurisdictional claims in published maps and institutional affiliations.

Ready to submit your research? Choose BMC and benefit from:

- fast, convenient online submission

- thorough peer review by experienced researchers in your field

- rapid publication on acceptance

- support for research data, including large and complex data types

- gold Open Access which fosters wider collaboration and increased citations

- maximum visibility for your research: over $100 \mathrm{M}$ website views per year

At $\mathrm{BMC}$, research is always in progress.

Learn more biomedcentral.com/submissions 